\title{
Vapor Pressure and Heat of Sublimation of Tungsten
}

\author{
E. R. Plante and A. B. Sessoms \\ Institute for Materials Research, National Bureau of Standards, Washington, D.C. 20234
}

(November 30, 1972)

\begin{abstract}
The vapor pressure of tungsten was measured by the Langmuir method in the temperature range 2600 to $3100 \mathrm{~K}$ using a vacuum microbalance. Four series of data gave concordant results and three of the four series gave second and third law heats of sublimation in excellent agreement. A vapor pressure equation representing the data is $\log P(\mathrm{~atm})=-45385 / T+7.871$, based on our mean third law heat and tabulated entropies at $2800 \mathrm{~K}$. The mean third law heat of sublimation at $298.15 \mathrm{~K}$ is $205.52 \pm 1.1$ $\mathrm{kcal} \mathrm{mol}^{-1}\left(859.90 \pm 4.6 \mathrm{~kJ} \mathrm{~mol}^{-1}\right)$ where the uncertainty is an overall estimated error. Rates of vaporization are about $1 / 2$ those previously accepted for tungsten.
\end{abstract}

Key words: Heat of sublimation; Langmuir vaporization; rate of vaporization; tungsten; vapor pressure.

\section{Introduction}

This study was undertaken as part of an NBS contribution to a program involving the measurement of vapor pressures of selected standard materials in various cooperating laboratories. The object of these measurements is to determine reliable standard vapor pressure data and to reveal, if possible, any systematic differences in vapor pressures which might be attributable to different methods of measurement. Currently, gold, and cadmium and silver [1] ${ }^{1}$ have been certified as standard reference materials for vapor pressure measurements. Certification of standards for platinum and tungsten are in process and are expected to be available in the near future [2].

Data leading to vapor pressures or heats of sublimation of tungsten have been reported by a number of investigators [3-9] using the Langmuir method. In addition, Golubtsov and Nesmeyanov [8] measured the vapor pressure by the Knudsen method. Thermodynamic data resulting from these and the current measurements are summarized in table 2 and discussed in section 4 of this paper.

\section{Experimental Method}

Data were obtained by Langmuir rate of sublimation measurements using a vacuum microbalance. Vacuum in the range $10^{-7}$ to $10^{-9}$ torr was maintained and indicated by a commercial sputter-ion pump. Techniques and procedures were similar to those outlined previously [10].

The tungsten SRM-749 stock material is in excess of 99.99 percent purity. Additional information will be included in the provisional NBS Certificate of Analysis. Samples were machined by arc erosion into

\footnotetext{
' Figures in brackets indicate the literature references at the end of this paper.
}

right circular cylinders having nominal diameters of 0.25 and $0.20 \mathrm{~cm}$ and length of $1.9 \mathrm{~cm}$. A hole 0.1 $\mathrm{cm}$ in diameter and $1.5 \mathrm{~cm}$ long, assumed to represent blackbody conditions, was drilled along the cylinder axis and a suspension hole was drilled along a diameter about $0.20 \mathrm{~cm}$ from the other end.

The sample was suspended from one arm of an equal-arm quartz ${ }^{2}$ beam microbalance by a chain of $0.025 \mathrm{~cm}$ diameter sapphire or quartz rods connected together by $\mathrm{V}$-shaped hooks made by heating and bending the rods. The lower $10 \mathrm{~cm}$ of the suspension was $0.005 \mathrm{~cm}$ tungsten wire which passed through the suspension hole in the samples and over the hook on the lowest suspension rod.

The appendage of the vacuum chamber in which the sample hung was a $20 \mathrm{~mm}$ O.D. Vycor $^{3}$ tube made with a fused silica window at the bottom. The window could be protected during sublimation experiments by a magnetically operated shutter; however, because the shutter must be kept open for a large fraction of the time during short experiments when the rate of vaporization is highest, the shutter was left open during all the experiments reported here. To afford some additional protection to the window, the side arm was extended so that the bottom of the sample was about $22.5 \mathrm{~cm}$ from the window. With this experimental arrangement changes in the window correction factor are not significantly larger than in those cases where an attempt was made to protect the window.

Data were designated as belonging to a new experimental series when new window correction values were determined and when a sample was changed. The purpose of changing samples was to

\footnotetext{
${ }^{2}$ The terms quartz and fused silica are used interchangeably in this paper for fused

${ }^{3}$ Refica:
${ }^{3}$ efence to trade names is made only for completeness of description and does not imply in any way the endorsement of the product by the National Bureau of Standards.
} 
check on reproducibility of the measurements and to see if changes in the rate of sublimation could be detected for slightly different length to radius ratios of the samples because of temperature inhomogeneity.

Prior to experiments, a thin platinum coating which did not heat inductively was deposited on the interior surface of the Vycor tube, and a grounding device, consisting of a split circular stainless steel ring with a magnetically actuated wire hinge, was positioned in the Vycor tube so that it made contact with the platinum coating. The Vycor tube was connected to the vacuum system by means of a standard taper joint using Apiezon W sealant. A wire connected the grounding device to an electrical ground. With the sample in place the hinge of the grounding device could be magnetically deflected until it made contact with the wire supporting the sample. This allowed for removal of any static charge generated during the high temperature heating. Heating was accomplished by induction of $450 \mathrm{kHz}$. The metal sample served as its own susceptor.

Temperatures were measured with an NBS-calibrated optical pyrometer through a calibrated window and mirror. Calibration corrections for the window and mirror were determined in separate experiments using a band lamp. Corrections were determined in terms of " $A$ " values where $A=(1 / T)-\left(1 / T_{w}\right) ; T$ is the brightness temperature of the source and $T_{w}$ is the brightness temperature of the source with the window or mirror in the optical path. Window corrections were determined before and after each series of measurements and the average value accepted. Mirror corrections were determined less frequently; an average of two independent sets of determinations was used. Corrections applied to the observed temperature because of the change in the window " $A$ " value during an experimental series were less than $4 \mathrm{~K}$ at $2800 \mathrm{~K}$.

In obtaining each datum point the following sequence of operations was followed: (1) the rest point of the balance was determined, (2) the sample was heated to the base temperature, a temperature about $100 \mathrm{~K}$ below the lowest temperature where sublimation rate measurements were practicable, (3) an operating temperature of the sample was attained by adjusting the heater power and holding it constant at a predetermined setting, (4) the power was turned off, (5) the sample and platinum coating on the Vycor sleeve were grounded, and (6) the rest point of the balance was redetermined.

The mass change of the sample was determined from the displacement of the beam of the microbalance and the previously determined sensitivity which was about $0.5 \mu \mathrm{g} / \mu \mathrm{m}$. The change in sensitivity with load is negligible for the weight change (about $2 \mathrm{mg}$ ) during a series of experiments. Data during these experiments were obtained with a gold plated balance used in previous experiments. This balance exhibited excellent zero point stability in contrast to some previous drift problems [11]. This is attributed to a more nearly constant room temperature at our new facility, use of a narrower slot on the kinematic table which supported the balance, and the grounding procedure which eliminates static charge on the sample and its surroundings.

Initial time for an experiment was taken when the brightness of the blackbody hole matched the brightness of the pyrometer filament previously set for a temperature $50 \mathrm{~K}$ below the expected operating temperature for a particular power setting. Final time was taken as the time the power was turned off. The first temperature measurement was usually obtained within the first minute of the experiment, at which time the sample had attained its operating temperature. This method of determining the duration of the experiment was used because the rate of heating is slower than the rate of cooling.

Experimentally it is observed that the time required to heat from the base temperature to the operating temperature is shorter, the greater is the temperature difference between them. This probably is due to the fact that the power input can be changed almost instantaneously, the power loss is proportional to $T^{4}$, and the energy absorbed by the sample during warm up becomes a smaller fraction of the energy input as the temperature difference gets larger. For low temperature runs the length of time to go from the base temperature to $50 \mathrm{~K}$ below the operating temperature would be about 15 seconds while for high temperature runs about 3 seconds would be required. This method of timing tacitly assumes that the excess weight lost in heating from the base temperature to $50 \mathrm{~K}$ below the operating temperature exactly balances the deficiency in weight lost in going from $50 \mathrm{~K}$ below the operating temperature to the operating temperature. We have assumed that systematic error resulting from this approximation is negligible.

\section{Thermodynamic Treatment of Data}

Vapor pressures were calculated using the equation ${ }^{4}$

$$
P=\frac{m}{\alpha a t}\left(\frac{2 \pi R T}{M}\right)^{1 / 2}
$$

where $m$ is the mass of material sublimed, $t$ is the duration of the experiment, $a$ is the projected surface area of the sample, $T$ is the temperature on the IPTS-68 scale [12], $R$ is the gas constant, $M$ is the atomic weight of the vaporizing species, monatomic tungsten, and $\alpha$ is the vaporization coefficient which we assumed is equal to unity. The value of the sample area at temperature, $A_{T}$, was calculated using the equation

$$
A_{T}=A_{R}[1+2 \beta(T-300)]
$$

where $A_{R}$ is the area calculated from measurements made at room temperature and $\beta$ is the linear thermal expansion coefficient. For tungsten $\beta$ was taken to be $6.0 \times 10^{-6} \mathrm{~K}^{-1}$. This correction amounts to an increase in the sample surface area of 2 to 4 percent at sublimation temperatures.

${ }^{4}$ Values of constants used in the equation were: $R=1.98717 \mathrm{cal} \mathrm{mol}^{-1} \mathrm{~K}^{-1}$ or 8.3143 $\mathrm{Jmol}^{-1} \mathrm{~K}^{-1}$, atomic weight of tungsten $=183.85$; one standard atmosphere $=101,325 \mathrm{Nm}^{-2}$. 
Areas at room temperature were $1.30 \mathrm{~cm}^{2}$ and 1.64 $\mathrm{cm}^{2}$ for the nominal $0.20 \mathrm{~cm}$ and $0.25 \mathrm{~cm}$ diam samples respectively.

A linear equation was fitted to the data by least squares solution of the approximate integrated form of the Clausius-Clapeyron equation

$$
\log P(\operatorname{atm})=-\frac{\Delta H^{\circ}}{R^{\prime} T}+\frac{\Delta S^{\circ}}{R^{\prime}}
$$

where $\Delta H^{\circ}$ and $\Delta S^{\circ}$ are the heat and entropy changes at an average temperature and $R^{\prime}$ is $R \ln 10$.
In addition, third law heats of sublimation were calculated using the equation

$$
\Delta H_{298}^{\circ}=T\left[\Delta\left(-\frac{G_{T}^{\circ}-H_{298}^{\circ}}{T}\right)-R \ln P(\operatorname{atm})\right]
$$

where $\Delta-\left(G_{T}^{\circ}-H_{298}^{\circ}\right) / T$ is the difference in free energy functions of product and reactant. Free energy function data were from JANAF [13]. Finally, accurate second law heats and entropies were obtained using a method suggested by Horton [14] which is similar to Cubicciotti's method [15]. This consists of fitting by

\begin{tabular}{|c|c|c|c|c|c|}
\hline \multicolumn{6}{|c|}{ Vapor pressure of tungsten SRM $749,0.20 \mathrm{~cm}$ sample series I } \\
\hline $\begin{array}{l}\text { Temp } \\
\text { Kelvins }\end{array}$ & $\begin{array}{c}\text { Time } \\
\text { Seconds }\end{array}$ & $\begin{array}{l}\text { Wgt loss } \\
\text { Micrograms }\end{array}$ & $\begin{array}{c}\text { Pressure } \\
\text { Atmospheres }\end{array}$ & $\begin{array}{r}\Delta H(298) \\
\mathrm{cal} / \mathrm{mol}\end{array}$ & $\begin{array}{c}\Delta H(298) \\
\mathrm{J} / \mathrm{mol}\end{array}$ \\
\hline $\begin{array}{l}2879 \\
2691 \\
2946 \\
2756 \\
2627 \\
2990 \\
2799 \\
2880 \\
2567 \\
3026 \\
2843 \\
2876\end{array}$ & $\begin{array}{r}300 \\
3600 \\
300 \\
3600 \\
10800 \\
240 \\
1200 \\
600 \\
14400 \\
180 \\
900 \\
600\end{array}$ & $\begin{array}{c}53.7 \\
56.1 \\
127 \\
139 \\
68.9 \\
160 \\
80.8 \\
123 \\
31 \\
190 \\
103 \\
98.7\end{array}$ & $\begin{array}{l}1.19000 \mathrm{E}-8 \\
1.01000 \mathrm{E}-9 \\
2.85000 \mathrm{E}-8 \\
2.52000 \mathrm{E}-9 \\
4.07000 \mathrm{E}-10 \\
4.52000 \mathrm{E}-8 \\
4.43000 \mathrm{E}-9 \\
1.37000 \mathrm{E}-8 \\
1.36000 \mathrm{E}-10 \\
7.20000 \mathrm{E}-8 \\
7.58000 \mathrm{E}-9 \\
1.10000 \mathrm{E}-8\end{array}$ & $\begin{array}{l}205932 \\
205533 \\
205656 \\
205544 \\
205334 \\
206014 \\
205650 \\
205198 \\
206179 \\
205715 \\
205879 \\
206165\end{array}$ & $\begin{array}{l}861620 \\
859949 \\
860463 \\
859998 \\
859116 \\
861965 \\
860438 \\
858549 \\
862652 \\
860712 \\
861400 \\
862593\end{array}$ \\
\hline \multicolumn{6}{|c|}{ Vapor pressure of tungsten, SRM $749,0.25 \mathrm{~cm}$ sample series II } \\
\hline $\begin{array}{l}2760 \\
2927 \\
2796 \\
2865 \\
2983 \\
2710 \\
2667 \\
2590 \\
2628\end{array}$ & $\begin{array}{r}1200 \\
240 \\
1200 \\
480 \\
120 \\
2400 \\
4500 \\
10800 \\
7200\end{array}$ & $\begin{array}{c}67 \\
98.8 \\
102 \\
88.8 \\
100 \\
68.4 \\
69.3 \\
49.4 \\
57\end{array}$ & $\begin{array}{l}2.89000 \mathrm{E}-9 \\
2.19000 \mathrm{E}-8 \\
4.43000 \mathrm{E}-9 \\
9.74000 \mathrm{E}-9 \\
4.47000 \mathrm{E}-8 \\
1.46000 \mathrm{E}-9 \\
7.84000 \mathrm{E}-10 \\
2.30000 \mathrm{E}-10 \\
4.00000 \mathrm{E}-10\end{array}$ & $\begin{array}{l}205095 \\
205850 \\
205427 \\
206061 \\
205594 \\
205016 \\
205021 \\
205346 \\
205503\end{array}$ & $\begin{array}{l}858116 \\
861275 \\
859505 \\
862159 \\
860204 \\
857785 \\
857807 \\
859166 \\
859826\end{array}$ \\
\hline \multicolumn{6}{|c|}{ Vapor pressure of tungsten SRM $749,0.20 \mathrm{~cm}$ sample series III } \\
\hline $\begin{array}{l}2857 \\
2796 \\
2931 \\
2633 \\
2983 \\
2712 \\
2733 \\
2670 \\
2569 \\
3008\end{array}$ & $\begin{array}{r}600 \\
1200 \\
180 \\
10800 \\
180 \\
3000 \\
2100 \\
5400 \\
16200 \\
180\end{array}$ & $\begin{array}{l}93 \\
81.4 \\
63 \\
76.6 \\
128 \\
68.2 \\
62.6 \\
67 \\
44.1 \\
180\end{array}$ & $\begin{array}{l}1.03000 \mathrm{E}-8 \\
4.46000 \mathrm{E}-9 \\
2.35000 \mathrm{E}-8 \\
4.53000 \mathrm{E}-10 \\
4.32000 \mathrm{E}-8 \\
1.47000 \mathrm{E}-9 \\
1.94000 \mathrm{E}-9 \\
7.98000 \mathrm{E}-10 \\
1.72000 \mathrm{E}-10 \\
6.80000 \mathrm{E}-8\end{array}$ & $\begin{array}{l}205162 \\
205389 \\
205723 \\
205248 \\
205147 \\
205132 \\
205231 \\
205160 \\
205143 \\
204824\end{array}$ & $\begin{array}{l}858400 \\
859349 \\
860744 \\
858756 \\
858335 \\
858271 \\
858685 \\
858390 \\
858316 \\
856983\end{array}$ \\
\hline \multicolumn{6}{|c|}{ Vapor pressure of tungsten SRM $749,0.25 \mathrm{~cm}$ sample series IV } \\
\hline $\begin{array}{l}2812 \\
2955 \\
2637 \\
2895 \\
2734 \\
2688 \\
2775 \\
2577 \\
3067 \\
3013\end{array}$ & $\begin{array}{r}600 \\
240 \\
7200 \\
300 \\
2400 \\
3600 \\
1500 \\
10800 \\
120 \\
180\end{array}$ & $\begin{array}{l}68.1 \\
144 \\
62 \\
89.4 \\
77.8 \\
65.3 \\
91.2 \\
39.4 \\
248 \\
196\end{array}$ & $\begin{array}{l}5.93000 \mathrm{E}-9 \\
3.21000 \mathrm{E}-8 \\
4.36000 \mathrm{E}-10 \\
1.58000 \mathrm{E}-8 \\
1.67000 \mathrm{E}-9 \\
9.27000 \mathrm{E}-10 \\
3.16000 \mathrm{E}-9 \\
1.83000 \mathrm{E}-10 \\
1.12000 \mathrm{E}-7 \\
5.87000 \mathrm{E}-8\end{array}$ & $\begin{array}{l}204985 \\
205591 \\
205763 \\
205457 \\
206121 \\
205759 \\
205729 \\
205472 \\
205831 \\
206047\end{array}$ & $\begin{array}{l}857655 \\
860192 \\
860914 \\
859633 \\
862410 \\
860895 \\
860771 \\
859696 \\
861197 \\
862103\end{array}$ \\
\hline
\end{tabular}

TABLE 1. Compilation of tungsten data ${ }^{\text {a }}$

a Data are listed in experimental sequence. 
least squares $\Delta-\left(G_{T}^{\circ}-H_{298}^{\circ}\right) / T-R \ln P$ versus $1 / T$ and allowing for nonzero intercept. The slope corresponds to an accurately adjusted second law heat while the intercept corresponds to $\Delta S_{298}^{\circ} \quad(3 \mathrm{~d}$ law) $-\Delta S_{298}^{\circ}$ (2d law) [10].

\section{Results}

Basic data, the vapor pressures calculated using eq (1) and individual third law heats calculated using eq (3) are listed in table 1 . Table 2 lists the second law heat and entropy change at $298.15 \mathrm{~K}$ calculated by Cubicciotti's method and their standard errors, the coefficients of eq (2) and their standard errors, the standard deviation in the pressure in $\log$ units, and the average third law heat and its standard error for each series of data. The mean third law heat at 298.15 $\mathrm{K}$, calculated as the average of the means for each run, is $205.52 \mathrm{kcal} \mathrm{mol}^{-1}\left(859.90 \mathrm{~kJ} \mathrm{~mol}^{-1}\right)$ while the average second law heat and entropy change at 298.15 $\mathrm{K}$ based on the four series of data are $204.15 \mathrm{kcal} \mathrm{mol}^{-1}$ $\left(854.16 \mathrm{~kJ} \mathrm{~mol}^{-1}\right)$ and $33.25 \mathrm{cal} \mathrm{mol}^{-1} \mathrm{~K}^{-1}(139.08 \mathrm{~J}$ mol $^{-1} \mathrm{~K}^{-1}$ ) respectively. As usual, the third law heat is considered more reliable than the second law heat.

It may be of interest to indicate the uncertainty in the pressures, temperatures, mean third law heat, and the second law heat and entropy change. The standard deviation in $P$ as computed by the law of propagation of errors [17] applied to equation (1) has components of error due to random error in $m, t, T$ and systematic error in $a$. For a typical experiment at $2800 \mathrm{~K}$, respective standard deviations of 2 percent, 2 percent, 0.07 percent $(2 \mathrm{~K})$, and 1 percent are reason- able estimates based on the experimental observations for the above quantities. These combine to give a standard deviation in the pressure of 3 percent. It is important to note that this estimated standard deviation will be too small because it applies to an experiment in which $T$ is constant and in which only estimates of the value of $T$ vary. However, in practice, some real fluctuation in $T$ may occur and the rate of evaporation is not independent of real fluctuations in $T$.

A more realistic estimate of the error in $P$ is given by the standard deviation obtained by least squares fit of eq (2). For the four runs reported here, standard deviations in the range 4-7 percent are observed. Application of the law of propagation of errors to eq (2) shows that a standard deviation in $T$ of $1 \mathrm{~K}$ would result in a standard deviation in $P$ of 1.3 percent at $2800 \mathrm{~K}$. The standard deviation in $P$, calculated from the least squares fit of eq (2), can be considered as arising from two sources. Part is due to measurement errors in the pressure itself which was estimated as 3 percent and the remainder is due to error in the temperature measurements. If the resultant error in the pressure is calculated as the square root of the sum of the squares, a standard deviation of $4 \mathrm{~K}$ in the mean temperature would give a standard deviation of 6 percent which agrees well with the observed range of 4-7 percent.

The standard deviation in the mean temperature of an experiment can be computed from the temperature observations for each experiment and these show that standard deviations in the mean temperature of an experiment seldom exceed $2 \mathrm{~K}$. The standard deviation in the temperature of an experiment thus

TABLE 2. Derived quantities for tungsten ${ }^{\text {a }}$

\begin{tabular}{|c|c|c|c|c|c|c|c|c|c|c|c|}
\hline & \multicolumn{9}{|c|}{ Second law values } & \multicolumn{2}{|c|}{ Third law values } \\
\hline & $\begin{array}{c}\Delta H^{\circ}(298) \\
\mathrm{kcal}^{-1} \\
\mathrm{~mol}^{-1}\end{array}$ & $\begin{array}{l}\text { S.E. } \\
\text { kcal } \\
\text { mol-1 }^{-1}\end{array}$ & $\begin{array}{c}\Delta S^{\circ}(298)^{\mathrm{c}} \\
\mathrm{cal} \mathrm{mol}^{-1} \\
\mathrm{~K}^{-1}\end{array}$ & $\begin{array}{c}\text { S.E. } \\
\text { cal mol-1 } \\
\mathrm{K}^{-1}\end{array}$ & $\begin{array}{c}-\Delta H_{T}^{\circ} / R^{\prime} \\
\mathbf{K}\end{array}$ & $\underset{\mathrm{K}}{\mathrm{S.E}}$ & $\Delta S_{T}^{\circ} / R^{\prime}$ & S.E. & $\begin{array}{c}\text { S.D. } \\
(\log P)\end{array}$ & $\begin{array}{c}\Delta H^{\circ}(298) \\
\mathrm{kcal}^{-1} \\
\mathrm{~mol}^{-1}\end{array}$ & $\begin{array}{l}\text { S.E. } \\
\text { kcal } \\
\text { mol-1 }^{-1}\end{array}$ \\
\hline $\begin{array}{l}\text { Series I .20 } \\
\quad \text { cm }\end{array}$ & 205.33 & 1.94 & 33.60 & 0.69 & 45345 & 428 & 7.840 & 0.152 & 0.026 & 205.73 & 0.09 \\
\hline $\begin{array}{l}\text { cm } \\
\text { Series III . } 20\end{array}$ & 201.12 & 2.28 & 32.18 & .83 & 44427 & 502 & 7.531 & .181 & .025 & 205.44 & .12 \\
\hline $\begin{array}{l}\text { cm } \\
\text { Series IV } 25\end{array}$ & 205.16 & 1.41 & 33.72 & .51 & 45307 & 305 & 7.866 & .110 & .018 & 205.22 & .07 \\
\hline $\begin{array}{l}\text { cm } \\
\text { Means, this }\end{array}$ & 204.98 & 1.96 & 33.49 & .70 & 45255 & 431 & 7.812 & .154 & .027 & 205.68 & .10 \\
\hline $\begin{array}{l}\text { work } \\
\text { Swarcz et al. }\end{array}$ & 204.15 & $\mathrm{~d} 2.0$ & 33.25 & d .70 & & & & & & 205.52 & ${ }^{\mathrm{d}} 1.1$ \\
\hline [6] & 202.55 & 2.74 & 34.14 & .96 & 44706 & 601 & 7.773 & .212 & .045 & 203.69 & .18 \\
\hline Deadmore [7] & 216.43 & 9.19 & 37.94 & 3.22 & 47737 & 2004 & 8.777 & .702 & .102 & 204.39 & .50 \\
\hline $\begin{array}{l}\text { Zwikker [5] } \\
\text { Langmuir }\end{array}$ & 214.95 & 1.41 & 38.10 & .50 & 47445 & 306 & 8.821 & .109 & .037 & 202.54 & .33 \\
\hline $\begin{array}{l}{[3,4]} \\
\mathrm{G} \text { and N [8] } \\
\text { Knudsen data } \\
\quad[8] \\
\text { ZIT [9] }\end{array}$ & 204.51 & 3.80 & 34.67 & 1.30 & $\begin{array}{l}45141 \\
45526 \\
\\
44766 \\
43333\end{array}$ & 819 & $\begin{array}{l}8.064 \\
8.074 \\
7.845\end{array}$ & .280 & .070 & 201.78 & .27 \\
\hline
\end{tabular}

a All temperatures were converted to IPTS-68 scale.

b S.D. = Standard deviation of a single measurement; S.E. = standard error (standard deviation in the mean).

${ }^{c}$ Based on tabulated data, $\Delta S^{\circ}(298)=33.74 \mathrm{cal} \mathrm{mol}^{-1} \mathrm{~K}^{-1}$.

d These errors are based on twice the standard error.

e Original data were supplied by author. 
appears to be 2 to 3 times larger than that estimated from the temperature observations. This is probably due in part to the gradual increase in $A$ value of the window during an experimental series which biases the observed temperatures toward lower values as an experimental series progresses, but which will show up as a random error because of random selection of temperatures. A second contributing factor is that the operator's judgment of what constitutes a match in brightness of the pyrometer filament with the blackbody hole varies with temperature and from day to day.

Estimates of the errors in second law heats and entropy changes can be made using several methods. Assuming that the effect of systematic error is negligible as compared to random error for the second law method, errors based on twice the standard error in the average of the four series are $2.0 \mathrm{kcal}$ and 0.7 cal $\mathrm{mol}^{-1} \mathrm{~K}^{-1}$ respectively.

Experience has shown that the uncertainty in the third law heat arising from systematic errors is usually greater than or comparable to the uncertainty arising from random errors. Thus, an estimate of the error in the mean third law heat will have to include both. An estimate of the random error can be made by applying the law of propagation of errors to eq (3). In doing so, we assume that there is no significant error in the free energy functions and their variation with temperature is negligible. Based on estimates of a 3 percent standard deviation in pressure and a $4 \mathrm{~K}$ standard deviation in temperature, the standard deviation in $\Delta H_{298}^{\circ}$ evaluated from data at $2800 \mathrm{~K}$ is 340 cal. For 10 data points this corresponds to a standard error of $110 \mathrm{cal}$ in the mean third law heat, which agrees well with values derived from the individual series. If there were no between run bias, the standard error in the mean third law heat derived from all four series and based on within run uncertainty would be $100 \mathrm{cal}$ while the observed value is $200 \mathrm{cal}$. This discrepancy is due to a between run systematic error of $2.5 \mathrm{~K}$ in the window and mirror correction factors which leads to an additional uncertainty of $170 \mathrm{cal}$. The largest uncertainty is due to systematic error in temperature measurement. Part of this error results from the uncertainty in the NBS calibration but most results from our inability to transfer this scale to laboratory measurements without error. The uncertainty in the pyrometer calibration at $2800 \mathrm{~K}$ is $7 \mathrm{~K}$ and we assume an additional systematic error of $14 \mathrm{~K}$ results in the process of carrying out measurements. These errors are presumed to represent 2 standard deviations and lead respectively to uncertainties of $500 \mathrm{cal}$ and $1000 \mathrm{cal}$ in the mean third law heat. If we use 2 standard deviations as the measure of uncertainty, then the uncertainty is $\left(200^{2}+340^{2}+500^{2}+1000^{2}\right)^{1 / 2}=1100 \mathrm{cal}(4600 \mathrm{~J})$. If this error is expressed in terms of temperature or pressure, it corresponds to an error in temperature of $15 \mathrm{~K}$ or an error in pressure of 22 percent.

This procedure for estimating the uncertainty in the third law heat deviates from some of our previous estimates $(6,10,11)$ because it assumes a much larger component of systematic error than we have previously estimated. The present method however, appears justified since it is well known that mean third law heats measured in different laboratories frequently disagree within the stated error limits when these limits are based on random error only.

Pressures obtained in this work are about one half those previously reported from this laboratory. This pressure difference corresponds to temperatures in the present work being systematically higher than those previously measured by about $30 \mathrm{~K}$ at $2800 \mathrm{~K}$. An error of this magnitude is most likely due to an error in temperature measurement and could result from an improperly determined $A$ value, deposition of tungsten on the window, or temperature inhomogeneity of the sample. Duplicate determinations as well as variation in the length to radius ratio of the two samples should prevent such an error from being important in the present work.

The spread in the average third law heats in these series amounts to $0.5 \mathrm{kcal}$ and this appears reasonable considering the standard errors and the small component of systematic error resulting from different window and mirror factors. Comparison of second law heats with third law heats shows good agreement in three of the four series with series 2 showing questionable agreement depending on ones interpretation of the significance of the standard errors. The vapor pressure data of tungsten is adequately represented by

$$
\log P(\mathrm{~atm})=-\frac{45385}{T}+7.871
$$

based on our mean third law heat and entropy data from JANAF [13] centered on $2800 \mathrm{~K}$. This equation gives pressures agreeing within 10 percent of pressures derived from least squares equations of each of the experimental series in the experimental temperature range.

Analysis of the older tungsten data was made by Szwarc et al. [6]. In the present work temperatures were converted to the IPTS-68 scale using data given in [12], and free energy function data from JANAF [13] were used to compute the value of the properties listed in table 2. These corrections increase the average third law heat by about $300 \mathrm{cal}$ but have little effect on the second law heats.

Other data listed in table 2 shows quite good agreement with the present results. Considering the time span and the temperature range involved the agreement is quite satisfactory. Deadmore [7] measured rates of sublimation of tungsten to use as a standard for comparison with rates of evaporation of $\mathrm{TaC}$, $\mathrm{HfC}$, and HfC-TaC solid solutions. His third law results are in good agreement with those presented here while his second law heat indicates some systematic error. Golubstov and Nesmeyanov [8] measured rates of sublimation by both the Langmuir and Knudsen method using nuclear activation analysis and studied the apparent vapor pressure as a function of ambient pressure in the system. They concluded that the apparent pressure was not a function of ambient pressure at pressures below $10^{-7}$ torr and the second law values for these conditions derived from their $\log P$ versus $1 / T$ equations agree well with those in the present study. It is of interest to note also that 
their data indicate unit sublimation coefficient for tungsten which all Langmuir measurements have previously only assumed. Values for the heat of sublimation determined mass spectrometrically by Zandberg et al. [9] are in satisfactory agreement for second law results. The older results of Langmuir [3, 4] and Zwikker [5] are in reasonable agreement with our results considering their experimental difficulties of measuring surface temperatures and establishing a temperature scale.

Our experiments indicate a heat of sublimation of tungsten about $2 \mathrm{kcal} \mathrm{mol}^{-1}$ higher than any of the previous results. Because of this difference, we have considered likely sources of systematic error very carefully. The effect of temperature gradients in a freely radiating cylindrical sample is without doubt the greatest unknown.

For an inductively heated, cylindrical specimen, the highest temperature should occur halfway up the cylinder axis. Temperatures above and below this should gradually decrease because of end effects. If a $1.0 \mathrm{~mm}$ diam blackbody hole terminated halfway up the cylinder axis, it would have a length to radius ratio of 18 and would give an excellent approximation to blackbody conditions if the specimen were isothermal. If the specimen is not isothermal and a blackbody hole extends beyond the center of the sample, the experimental temperature would probably be lower than that observed with a blackbody hole terminating at the center. Assuming a linear temperature gradient and neglecting the end areas which constitute only about 5 percent of the sample area, the optimum depth for a blackbody hole would be about 0.75 of the sample length. This depth would give an average temperature approximately equal to the average surface temperature of the sample. Our samples had blackbody holes about 79 percent of the sample length. Previous measurements by Szwarc et al. [6] used a sample having a blackbody hole extending 67 percent of the sample length. On the basis of the above arguments one would expect slightly lower apparent rates of vaporization in the measurements of Szwarc et al., than in our work. However, the reverse is true. This indicates either that temperature gradients in the samples were not important or that insufficient changes in geometry were made to expose their effects.

It is worth noting that because tungsten is the least volatile of all materials, it is difficult to imagine any experimental error which would lead to insufficient volatility. Thus, the most common errors such as reaction with ambient gases, deviation from blackbody conditions, and window contamination would all result in higher volatilities. This tends to support the lower volatilities obtained in the present work.

\section{References}

[1] Paule, R. C., and Mandel, J., Nat. Bur. Stand. (U.S.) Spec. Publ. 260-19 (1970), and Spec. Publ. 260-21 (1971).

[2] Cadmium, silver and gold standard reference materials (SRM 746,748 , and 745 resp.) may be purchased from the Office of Standard Reference Materials, National Bureau of Standards, Washington, D.C. 20234. Platinum (SRM 747) and tungsten (SRM 749) will be available after certification.

[3] Langmuir, I., Phys. Rev. 2, 329 (1913).

[4] Jones, H. A., Langmuir, I., and Mackay, G. M. J., Phys. Rev. 30, 201 (1927).

[5] Zwikker, C., Arch Ne'erl, Serie IIIA, 9 207-339 (1925).

[6] Szwarc, R., Plante, E. R., and Diamond, J. J., J. Res. Nat. Bur. Stand. (U.S.), 69A (Phys. and Chem.), No. 5, 417-421 (Sept.-Oct. 1965).

[7] Deadmore, D. L., J. Am. Ceram. Soc. 48, 357 (1965).

[8] Golubtsov, I. V., and Nesmeyanov, A. N., Vestn. Mosk. Univ., Ser. II, Khim [5], 31 (1965).

[9] Zandberg, E. Ya., Ionov, N. I., and Tontegode, A. Ya., Zh. Tekhn. Fiz. 35, 1504 (1965).

[10] Plante, E. R., Sessoms, A. B., and Fitch, K. R., J. Res. Nat. Bur. Stand. (U.S.), 74A (Phys. and Chem.), No. 5, 647-653 (Sept.-Oct. 1970).

[11] Plante, E. R., and Szwarc, R., J. Res. Nat. Bur. Stand. (U.S.) 70A, (Phys. and Chem.), No. 2, 175-179 (Mar.-Apr. 1966).

[12] The International Temperature Scale of 1968, Metrologia 5, 35 (1969).

[13] JANAF. Thermochemical Tables, The Dow Chemical Company, Midland, Michigan. Tungsten (c,g) tables dated June 30, 1966.

[14] Horton, W. S., J. Res. Nat. Bur. Stand. (U.S.) 70A (Phys. and Chem.) No. 6, 533-539 (Nov.-Dec. 1966).

[15] Cubicciotti, D., J. Phys. Chem. 70,2410 (1966).

[16] Kostkowski, H. J. and Lee, R. D., Nat. Bur. Stand. (U.S.), Monogr. 41, 31 pages (March 1962).

[17] Mandel, J., The Statistical Analysis of Experimental Data (Interscience Publishers, New York, 1964), pp. 72-75.

(Paper 77A2-766) 